\title{
Enhancing the Practical Relevance of Research
}

\section{Citation}

Toffel, Michael W. "Enhancing the Practical Relevance of Research." Harvard Business School Working Paper, No. 16-082, January 2016.

\section{Permanent link}

http://nrs.harvard.edu/urn-3:HUL.InstRepos:25525862

\section{Terms of Use}

This article was downloaded from Harvard University's DASH repository, and is made available under the terms and conditions applicable to Open Access Policy Articles, as set forth at http:// nrs.harvard.edu/urn-3:HUL.InstRepos:dash.current.terms-of-use\#OAP

\section{Share Your Story}

The Harvard community has made this article openly available.

Please share how this access benefits you. Submit a story.

Accessibility 
H A R VAR D

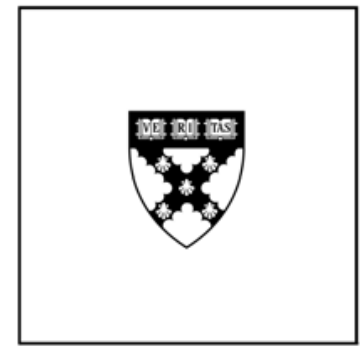

\title{
Enhancing the Practical Relevance of Research
}

\author{
Michael W. Toffel
}

\section{Working Paper}

16-082

January 21, 2016 


\title{
Enhancing the Practical Relevance of Research
}

\author{
Michael W. Toffel* \\ Harvard Business School \\ mtoffel@hbs.edu
}

January 21,2016

\begin{abstract}
This article seeks to encourage scholars to conduct research that is more relevant to the decisions faced by managers and policymakers. I define relevant research papers as those whose research questions address problems found (or potentially found) in practice and whose hypotheses connect independent variables within the control of practitioners to outcomes they care about using logic they view as feasible. I provide several suggestions for how scholars can enhance research relevance, including engaging practitioners in on-campus encounters, at managerial conferences, and at crossover workshops; conducting site visits and practitioner interviews; working as a practitioner; and developing a practitioner advisory team. I describe several ways that scholars can convey relevant research insights to practitioners, including presenting at practitioner conferences, writing for practitioners in traditional crossover journals and in shorter pieces like op-eds and blogs, and attracting the interest of those who write columns, blogs, and articles about research for practitioners. I conclude by describing a few ways that academic institutions can encourage more relevant research, focusing on journals, professional societies, and doctoral programs.
\end{abstract}

\section{Introduction}

The theme of the 2015 annual conference of the Production and Operations Management Society (POMS) was "Expanding POM research, teaching, and practice to help organizations, society, economies, and the environment"-in other words, relevance. This reflects the Society leadership's view that operations management $(\mathrm{OM})$ research needs to be more relevant to the world outside of academia.

I agree. Much of today's business school scholarship is far removed from the actual practice of management, and it seems especially odd that this is so true for OM scholarship too given this field's roots can be traced to applied research a century ago that aimed to improve production processes. Some of the most important research of that era was conducted by practitioners themselves, such as Frederick Taylor's scientific management work, Henry Gantt's

\footnotetext{
* I gratefully acknowledge helpful comments from Aaron Chatterji, Marshall Fisher, Jérémie Gallien, Andrew Hoffman, and Laurence Wein. Mailing address: Harvard Business School, Morgan Hall 415, Boston, MA 02163
} 
Gantt charts, and Ford W. Harris's economic order quantity (EOQ) model. Yet if you were to show today's OM managers the titles and abstracts from any recent issue of a top-tier OM journal, few would grant that we are studying what they do. Even a manager found a title promising, he or she would be hard pressed to learn anything from the article itself, given how far academic vernacular has drifted from ordinary English.

This article elaborates on my remarks at a plenary session of the 2015 POMS conference and provides my perspective on why research relevance matters, what relevance means in terms of a journal article, and how scholars can increase the relevance of their research. Preparing those remarks and this paper gave me a chance to take stock of practices that I and others have used to conduct research intended to be relevant to practice.

When I began considering what to say at the plenary session, I quickly discovered that the conference's call for greater relevance in OM scholarship builds on calls by some of the field's leading scholars to point the field toward more promising pastures by developing a stronger empirical base (Fisher 2007b) and to pursue more interesting projects (Cachon 2012). I also soon found that scholars of operations management and organizational studies have been expressing concern for several decades about how irrelevant most management scholarship is to practitioners. $^{1}$

Gene Woolsey was an early advocate of relevance in operations research (OR). A recent tribute noted that "Gene's position was that you, as an OR professional, shouldn't try to improve someone's process without getting experience with, and a good understanding of, that process. Consequently, Gene's students might find themselves riding along with Denver firefighters or working the late shift at a brewery.... Gene felt it was offensive to those running the process for an OR person to think he (she) could immediately step in and teach them how to improve that 
process" (Camm 2015: 369). ${ }^{2}$ Nearly 40 years ago, Hall and Hess (1978) were also expressing concerns of how operations research had grown increasingly disconnected from management practice. In 1993, Corbett and Van Wassenhove (1993) observed that Harvard Business Review's declining coverage of operations research topics coincided with the field's growing unease about its declining relevance. When Steven Graves became editor of Manufacturing \& Service Operations Management in 2009, he strongly encouraged more relevant research by calling for significantly more "papers that report on innovative implementations of OM research to real problems or that rigorously document existing practice and demonstrate how current modeling approaches succeed or fail in practice. I believe that our field is in desperate need of such work" (Graves 2009: 1).

In organizational studies, Janice Beyer, who would go on to become the editor of Academy of Management Journal and then president of the Academy of Management (AOM), lamented nearly 35 years ago that "increasing numbers of organizational scholars have begun to express concern that organizational/administrative science has had little effect on life in organizations" (Beyer 1982: 588). Thomas and Tymon (1982) noted that organizational studies (a) were not addressing phenomena or goals that practitioners faced and (b) were yielding results that were either obvious or unactionable. A decade later, the Academy of Management's 1993 presidential address - provocatively titled "What If the Academy Actually Mattered?"-referred to annual academic conferences as "an incestuous, closed loop" because scholars present research of interest only to each other (Hambrick 1994: 13). Around the same time, the inaugural issue of Organization Science opened with a lamentation that scholars were missing the opportunity to influence organizations, noting that " $[R]$ esearch on organizations has not typically focused on problems relevant to business and government organizations, and the real world of 
organizations has not drawn on the work undertaken by organizational scientists" (Daft and Lewin 1990: 1). This lack of managerial relevance of management research has also been noted internationally (e.g., Panda and Gupta 2014) and in the related field of strategic management when Vermeulen (2005: 979), for example, observed that "[b]y cutting practitioners as an audience out of the loop, we cut out reality from the academic cycle."

Apparently, this history of dissatisfaction has not been sufficient, as it continues to this day. In his 2000 AOM Presidential Address, Walsh observed that every year since Hambrick's 1993 remarks, the AOM conference has heard "president after president bemoan our irrelevance" (Walsh 2001: 216; examples include Mowday 1997 and Denisi 2010). Other recent examples include Gallien's (2013) call for more practice-focused research in operations management and Vizecky and El-Gayar's (2011) similar appeal to scholars of decision support systems. In 2014, New York Times columnist David Brooks wrote: “The most stinging dismissal of a point is to say: 'That's academic.' In other words, to be a scholar is, often, to be irrelevant"' (Brooks 2014). We can see, then, why the 2015 POMS conference chose its theme of urging more relevant research but can reasonably anticipate that its calls for greater relevance will not, on its own, bring much of a change.

This lack of influence doesn't reflect a lack of opportunity. As Brooks noted, "Some of the smartest thinkers on problems at home and around the world are university professors, but most of them just don't matter in today's great debates." It's a sentiment shared by many others. In a recent article in The Chronicle of Higher Education, University of Michigan's Andrew Hoffman called for professors to contribute to public and political debates "where expert knowledge can move the conversation forward" and noted that the scarcity of their contributions is "to the detriment of both the voting public and the academic community" (Hoffman 2015). 
Making operations management research more relevant to managers and policymakers requires all of us to reflect on our ambition as professors (or soon-to-be professors). Most of us would agree that our primary duties include teaching our students and generating new knowledge in our research. But the lack of practical relevance of much of our research might suggest that few of us also have the ambition to improve the decisions of the managers and policymakers whose actions we study. Hambrick's 1993 address said as much when he urged professors to choose research topics that could improve management practice, imploring business school faculty to "recognize that our responsibility is not to ourselves, but rather to the institutions around the world that are in dire need of improved management, as well as those individuals who seek to be the most effective managers they possibly can be.... It is time for us to matter" (Hambrick 1994: 13). As Cohen put it, this requires a change in attitude, from "Pay attention to what I do because I know what is important" to "How can I use my significant (academic) talents to help?" (Cohen 2007: 1017).

That Manufacturing \& Service Operations Management is currently developing a special issue on practice-focused research seems like a positive step, until we ask why the field needs a special issue to encourage high-quality OM research "focused on the practice of OM" (Gallien and Scheller-Wolf 2013: 1). Contrast this to the research conducted at another type of professional school that sits on many of campuses: The Journal of the American Medical Association (JAMA) does not require special issues to encourage medical scholars to conduct "research that helps doctors cure patients."

In the remainder of this article, I clarify what I mean by relevance in the context of a research paper and describe several approaches that have helped me and other scholars make our research more relevant. I then offer some suggestions for how scholars can communicate results 
of relevant research to practitioners. I conclude with some suggestions for how our journals, professional societies, and doctoral programs can foster more relevant research.

\section{Defining Relevant Research}

Anyone calling for more relevant scholarly research must clearly state what he or she means by relevance. I don't mean "impact" which academics often measure as citation count, as that assesses only how much attention a paper has attracted from fellow scholars. Instead, my

focus is on relevance to practice. ${ }^{3}$ To me, research is relevant if it has the potential to improve the decision making of managers or policymakers, a group to which I refer collectively as practitioners. The unit of analysis I am concerned with is a research paper intended to be published in a peer-reviewed journal, since such articles are the intellectual currency of the OM field. ${ }^{4}$ To me, research relevance is reflected in an article's research question, hypotheses, and implications.

\subsection{Relevance in Research Questions}

For those seeking to embark on a research project that will be relevant to practitioners, I suggest proceeding with a project only if you can answer "yes" to the following questions: ${ }^{5}$

1. Is the research question novel to academics? For example, would answering the question uncover new relationships between constructs, new nuances in relationships already known, or new mechanisms to better understand what drives those relationships?

2. Is the research question relevant to practice? Could answering the question actually influence the decisions of managers or policymakers? In other words, does the research seek "to solve a question of importance to practitioners working in that field"? (Vermeulen 2005: 980). Is the research focused on "problems and other issues that 
managers care about"? (Gulati 2007: 780). One should also be able to specify which practitioners in particular could benefit and how one knows that.

3. Can the research question be answered rigorously? For empirical work, one consideration is whether data are available with which to convincingly measure the constructs. Also, for research that seeks to reveal causal relationships and not mere correlations, does the context or data support a convincing identification strategy? For example, a study revealing that inventory levels are positively correlated with sales volumes is not nearly as informative to practitioner decision making as a causal study that reveals how inventory policies affect sales.

Of course, the first and third questions are familiar to scholars; what I want to emphasize is that scholarly novelty and rigor are just as important when considering which relevant research questions to pursue. As Van Mieghem (2013: 3) noted, the failure to pursue research questions relevant to more than just fellow scholars "carries the risk that research becomes an intellectual exercise in self gratification, i.e., the quintessential 'ivory tower' syndrome." These calls for greater relevance should not be misconstrued to imply that rigor need suffer. The decades-long debate (still going on in some quarters) about whether research should be relevant or rigorous poses a false choice: research needs to be both, a point others have been making for some time (Vermeulen 2005; Gulati 2007).

\subsection{Relevance in Hypotheses}

Relevant research hypotheses should have relevant consequents (measured as dependent variables) and relevant antecedents (measured as independent variables) and the proposed relationship between them should be sensibly grounded. 
Relevant research should hypothesize consequents that managers care about. Operations scholars know better than scholars in most other disciplines that practitioners care about performance across many domains, well beyond such financial indicators as stock price and sales volume. Classic examples include quality, labor utilization, on-time delivery, and productivity. Contemporary examples include occupational safety, environmental impact, and transparency.

As for antecedents, relevant research ought to consider the levers that practitioners actually have at their disposal. For example, many managers can implement specific activities, whether it be standardized programs such as the ISO 9001 Quality Management System Standard, tools such as statistical process control, or policies such as staffing rules, audit schemes, and training programs. But researchers seeking to examine the impact of bundles of activities such as supply chain capabilities bear the burden of conveying how such bundles can be implemented in the first place.

Relationships between consequents and antecedents should be grounded in the scholarly literature to be sure, but should also be grounded in reality. Does the flow of logical ideas that forms the rationale for your hypotheses resonate with at least some practitioners? If not, is that because your rationale is divorced from reality? As I will discuss below, listening carefully to practitioners' responses to proposed hypotheses can be very instructive. What do they find implausible and why? What alternative explanations do they offer? What conditions or limitations do they propose?

\subsection{Relevance in Implications}

Relevant research should articulate implications that encourage practitioners to take action based on the findings. Researchers should therefore state clearly how their results should influence practitioners' decisions, using specific examples when possible and circumscribing the 
circumstances under which the findings are likely to apply. This means including - and taking quite seriously_an "implications for practice" section in papers and, ideally, vetting drafts of this section with pertinent practitioners.

\section{Enhancing Research Relevance}

Choosing a research question that could be relevant is one thing. Conducting research that is relevant is another. Because scholars tend to have little or no work experience in the fields they study, we need ways to cross the gap between our perceptions and the workplace realities, including an understanding of what issues are most important and the challenges associated with implementing operational changes. One of the easiest ways to learn what is important to practitioners is to read the popular press and the industry press. For example, to learn what managers are thinking about with respect to environmental issues in their operations and supply chains, I read online newsletters and magazines aimed at environmental management professionals and environmentalists and I subscribe to updates about pending environmental laws and regulations. But that's just the tip of the iceberg. Dialogue and direct observation are better ways to figure out what research topics are relevant to practitioners, which independent variables are actually in their control, which outcomes they care about and how they typically measure them, and whether your rationale linking inputs to outcomes seems plausible. As Robert Hayes, a steadfast advocate for greater research relevance and tighter connections between academics and practitioners (Fisher 2007a), wrote, "we in academia have a great deal to learn from those out on the firing line - if we care to listen to them" (Hayes 1998: 96). Below, I describe several ways to accomplish that. 


\subsection{Create On-campus Encounters}

Many of us invite practitioners to guest lecture to our students, but such visits also provide an opportunity, perhaps while hosting our guest speakers for breakfast or lunch, to solicit feedback on our research ideas.

Student groups, too, invite practitioners to speak to student groups and at conferences they organize. Such visits provide additional opportunities for faculty to meet practitioners right on campus without having to manage the logistics. All we have to do is get on the email lists that announce these visits so that we can schedule a meeting with the speaker while he or she is on campus. I have found it critical to make these plans in advance because many practitioners schedule their visits fairly tightly around meetings arranged in advance.

For faculty at schools that offer executive education, those students — in one's own class or in others - are also the practitioners from whom we could be learning (Tushman and O'Reilly 2007). Identifying executive education students who could be helpful to you might require some coordination with the executive education program office. For example, faculty could share with those staff members the managerial roles and industries they wish to learn about, so that the staff can suggest particular participants.

\subsection{Attend Practitioner Conferences}

Academics rarely attend practitioner conferences — where managers or policymakers present to each other-but they should. Conferences provide an opportunity to learn what practitioners consider to be their own best practices and current challenges and how they react to potential solutions presented by others. ${ }^{6}$ I've also met policymakers and managers at workshops run by regulators. ${ }^{7}$ These conferences also provide low-stress networking opportunities to ask managers for quick feedback about your research ideas and hypotheses. These conversations can 
initiate enduring relationships that could, in turn, lead some of the practitioners to become members of your practitioner sounding board (described below).

\subsection{Attend Crossover Workshops}

"Crossover workshops" are one of the best ways for scholars to ensure that their research ideas and hypotheses are relevant to practice and grounded in reality. Crossover workshops bring practitioners and scholars together to discuss research and typically include scholars presenting both preliminary research ideas and late-stage research to solicit feedback from managers or policymakers, with these practitioners sharing the latest trends and challenges in the field and their "wish lists" of research questions that they would like answered. Because these events attract practitioners interested in academic research — and because of their smaller scale, typically involving 50-150 participants — scholars can (a) identify new research ideas and hypotheses, (b) network with practitioners who could then be on their sounding boards, and (c) find out what language and logic resonates with practitioners and — just as importantly—what does not.

Some of the longest-running OM crossover workshops are the Consortium for Operational Excellence in Retailing (COER), organized annually since 1998 by my Harvard colleague Ananth Raman and Wharton's Marshall Fisher, ${ }^{8}$ and the Service Supply Chain Thought Leaders Forum, organized several times since 2002 by Wharton's Morris Cohen. ${ }^{9}$ But because these events tend to be small and invitation-only, scholars interested in adopting this approach should consider organizing their own crossover workshops in their own subfields. For example, Jérémie Gallien (London Business School) and colleagues organized a “Collaborative Academic/Practitioner Workshop on Operational Innovation" for academics and practitioners to learn from successful academic-practitioner research collaborations. ${ }^{10}$ 
I have co-organized several crossover workshops and was impressed by how much I learned and by the interesting practitioners I met. John Mayo (Georgetown), Tom Lyon (University of Michigan), and I co-organized "Transparency and Accountability: The Role of Information Disclosure," bringing together scholars and regulators interested in the effectiveness of information disclosure on altering firms' operational behavior. ${ }^{11}$ Ginger Jin (University of Maryland) and I co-organized "Research on Effective Government: Inspection and Compliance," a workshop that assembled more than 100 scholars and regulators to discuss evidence-based approaches to bolster regulatory compliance. ${ }^{12}$ Scholars presented key findings from recent research, regulators provided feedback and suggested research questions they wanted answered, and members of both groups forged new relationships with each other.

\subsection{Conduct Field Visits and Practitioner Interviews}

Scholars can learn by directly observing what operations people do at work. Field work has a long tradition in many disciplines, perhaps most notably cultural anthropology and sociology, but also in OM; Fisher (2007b) profiles examples in the auto industry and other contexts. One might think it serves only to provide an empirical base for qualitative scholarly work and teaching cases. But field work can be very helpful to any OM scholar-including modelers and quantitative empiricists - because it involves observing practitioners in action, the problems they face, and the solutions they try. The chance to ask questions of practitionerswhat exactly is going on here and why? - can lead to more relevant research questions and hypotheses. $^{13}$

Each of us can take action on this front immediately. In my research that entails empirical analysis of archival data, my coauthors and I often interview practitioners to learn how they perceive the problems we are considering studying. We also seek their ideas for hypotheses and 
their feedback on our preliminary ideas. This has often led us to revise our initial questions and hypotheses to those that are more relevant to and well-grounded in the situation we are studying. We have also learned institutional details critical to identification strategies, such as how workers are assigned to tasks.

Faculty in schools that produce teaching cases can leverage site visits set up for case research to also ask practitioners about their research ideas. Others need to find ways to get themselves invited to field sites; a good start is to meet practitioners on campus and at conferences, as described above. OM scholars can take advantage of institutional initiatives designed to promote faculty access to field sites. At Harvard, for example, the Behavioral Insights Group fosters opportunities for faculty to collaborate with practitioners to conduct field experiments to improve organizational practices, while the Sustainability, Transparency, and Accountability Research (STAR) Lab does the same for scholars of those topics.

\subsection{Work as a Practitioner}

One of the best ways for scholars to learn the practical dimensions of the workplaces they are studying is to actually work as a practitioner through a short-term or part-time position, shifting one's role from an observer to an actor. A scholar interested in, say, ambulance scheduling could volunteer with an ambulance company to better understand the challenges its people face.

Dedicating substantial time to work as a practitioner is more common in some disciplines. Some economics professors and law professors take leaves of absence to assume government positions. This is not just for the occasional Larry Summers or Elizabeth Warren; there are many opportunities for junior and mid-career faculty. For example, many roles at the Council of Economic Advisors are filled by assistant and associate professors on leave from their 
ladder faculty positions. There are also opportunities to become resident and non-resident fellows and affiliates of think tanks such as the Brookings Institute, Resources for the Future, and the Public Policy Institute of California, which can, in turn, foster introductions to practitioners from whom scholars can obtain feedback on their research ideas.

\subsection{Develop a Sounding Board of Practitioners}

Many ideas in this section can provide ad hoc insights from practitioners, but even better would be to develop relationships with practitioners whom you can call upon regularly. For example, you could ask these practitioners whether your research questions strike them as important and, if not, how to improve them. You could also ask whether potential hypotheses are sensibly linking independent variables that they can control to dependent variables they actually care about and whether the logic underlying your hypotheses is well grounded in reality. As Fisher (2007b: 373) noted, "Something as simple as a conversation with a manager over lunch can be extremely useful in identifying problems and hypotheses for further investigation."

How do you assemble such a group? My practitioner advisory team includes former classmates who now work as environmental, health, and safety (EHS) managers; managers and regulators whom I met at practitioner conferences; and managers whom I met while writing teaching cases about their companies. Current and former students from undergraduate, MBA, and executive education programs can also be excellent sources of information about whether your research questions, mechanisms, and implications are relevant to practicing managers.

\subsection{Coauthor with Practitioners}

Operations management, more so than many other management fields, has a long tradition of working and coauthoring with practitioners. Such collaborations can not only provide access to proprietary data and nuanced interpretations of that information, but can also ground 
the research project in questions relevant to practice, produce papers depicting mechanisms and interpretations that seem plausible to practitioners, and generally intensify a practitionercollaborator's dedication to your project. Stanford's Laurence Wein (2009: 809), reflecting on his experience, notes how practitioner coauthors "contribute contextual details...that would have been impossible to find in the open literature." Gallien, Graves, and Scheller-Wolf (forthcoming) provide useful guidance on how to establish and manage successful relationships with collaborating practitioners.

\section{Conveying Relevant Insights to Practitioners}

When I was first exposed to academic journals in graduate school, I quickly discovered that despite business schools being referred to as "professional schools," no managers I knew were equipped — or patient enough — to decipher academic articles, laced as they were with jargon, math, and statistics. But surely, I presumed, there were mechanisms to convey the insights of the research in a more broadly intelligible and actionable way. It took me about a decade to realize how wrong I was and how little investment there is in such mechanisms.

How can scholars reach practitioners? Harvard Business School Dean Nitin Nohria, like other deans, meets with alumni all over the world. Over the past few years, he has been asking them where they learn the most useful ideas to improve their businesses. Not where they learn "good" ideas or "interesting" ideas, but ideas they have actually put into practice. In addition to Harvard Business Review, the answers Nohria hears most often include reports from the McKinsey Global Institute and other think tanks. TED Talks also make the list, as do managers at peer companies who share best practices at industry conferences and networking events. I would add to this list my conjecture that practitioners also learn a lot from the popular press and blogs they read, and from other crossover journals and conferences described below. 
This section offers three ways scholars can to convey research findings to the practitioners whose decisions they hope to influence: speaking at practitioner conferences, writing for publications read by practitioners, and attracting coverage by others who write for those publications.

\subsection{Present to Practitioners}

Presenting research at practitioner conferences lets you not only convey your insights directly to those whose decisions you want to influence, but also hear their questions and comments. This can help you sharpen your message and can trigger new relevant research. Presenting at practitioner conferences, I was usually one of the few academics there. These seem like an extremely underutilized opportunity to bridge the academic-practitioner divide. Scholars can contact conference organizers, who are often eager to find interesting speakers. Crossover conferences like COER, mentioned earlier, also offer beneficial access to practitioners.

There are also opportunities in less public settings, such as presenting research findings to executive education participants in class or over lunch and meeting face-to-face with managers and policymakers to brief them on your findings and insights. My coauthors Matt Johnson and David Levine and I have presented our research on occupational safety to OSHA managers; both they and we learned a lot. Wein (2009: 809) observes that while finding policymakers willing to meet with him to discuss his latest research findings is "extremely time-consuming and at times very contentious, I thinks it is quite likely that none of my work would have had any impact if I (or Ed Kaplan, in the case of our smallpox work) had stayed in my office."

\subsection{Write for Practitioners}

Crossover journals and the trade press. Harvard Business Review, Sloan Management Review, and California Management Review are the gold standard of crossover journals for some 
faculty because of their prestige and their circulation, not to mention their inclusion on the Financial Times journals list that some schools use to determine which publications count toward promotion. However, they cover only a very small fraction of OM research and their editorial scopes leave some topics not covered at all. Harvard Business Review and Sloan Management Review have also begun publishing shorter online-only articles that are often processed more rapidly, enabling faculty to post research insights in a more timely manner, but those lack the prestige of long-form articles published in the hardcopy magazines.

Narrower crossover journals provide another option. For example, Interfaces was launched in 1970 to "be informative, easy to read, brisk (for busy managers), topical, relevant, and professional... [and to] publish digests and highlights of current, interesting, and useful work in the world of managing and the management sciences" (Norden, 1970: 1). Its current submission guidelines call for papers "on the practice of operations research and management science (OR/MS) and the impact this practice has on organizations." Academy of Management Perspectives is a journal "aimed at the non-specialist academic reader with a secondary audience that include existing and future "thought leaders"”; it publishes articles that "synthesiz[e] and translat[e] theoretical and empirical research in management's distinct sub-fields in an authoritative evidential manner that makes these findings accessible for scholars outside that subfield [sic]." ${ }^{.14}$

Writing for these crossover outlets requires significant time and effort and can involve a lengthy editing process, a peer review process, or both, which makes this a substantial endeavor with an uncertain payoff. Fortunately, some of these outlets welcome proposals, which can save authors from wasting time developing pieces that the editors won't want. 
Trade journals and the popular press also offer academics a way to reach practitionersone that academics seldom use. Writing short articles aimed at practitioners can be fun because the sole objective is to convey the most important findings in an engaging manner. For example, Yale's Ed Kaplan has published in venues such as Interfaces and the Boston Globe about the implications of his research on the prevention of HIV transmission and terrorist attacks. ${ }^{15} \mathrm{I}$ have found it very rewarding to write short articles summarizing my research findings for venues such as The Guardian's “sustainable business" section, The Compass (a trade journal for health and safety professionals), The Atlantic, and European CEO. Such articles require a more conversational writing style than academics are accustomed to, but they have helped me hone the takeaways of my academic papers and better convey their value to practitioners.

Newspaper op-eds. Scholars conducting relevant research can also reach practitionersand the consumers and citizens who might influence them-through newspaper op-eds. Wein, who has written a series of New York Times op-eds describing policy prescriptions to stem pandemics — based on his research — notes that op-eds and the resulting media coverage can both educate the public and pressure policymakers to act on one's research findings.

Blogs and social media. Some OM professors have developed blogs to summarize the findings of their own and others' research and to analyze news items through an OM lens. Leading examples include:

- better operations: Thoughts on continuous improvement: from TPS to XPS by Norwegian University of Science and Technology's Torbjørn Netland at better-operations.com

- Ecommerce thoughts from Ann Arbor by University of Michigan's Amitabh Sinha at ecommerceaa.blogspot.com

- Global Supply Chain Musings by Purdue's Ananth Iyer at aviyer2010.wordpress.com

- Jay and Barry's OM Blog: A Blog for OM Educators by Jay Heizer (Texas Lutheran) and Barry Render (Rollins) at heizerrenderom.wordpress.com; also provides questions to prompt classroom discussion 
- The Operations Room by Northwestern's Marty Lariviere, Gad Allon, and Jan Van Mieghem at operationsroom.wordpress.com

- UCLA Anderson Global Supply Chain Blog by UCLA's Chris Tang, Felipe Caro, Charles Corbett, and colleagues at blogs.anderson.ucla.edu/global-supply-chain ${ }^{16}$

Many other disciplines have pursued this idea, with some of the resulting blogs attracting very wide audiences. University of Chicago's Steven Levitt and Stephen Dubner launched the "Freakonomics" blog and podcast (http://freakonomics.com/blog) to translate new findings from economic research in a clever and engaging manner, building on the momentum of their popular book of the same title. Penn Law's Cary Coglianese created the "RegBlog" website and enewsletter (www.regblog.org) to convey to practitioners and scholars insights from regulatory analyses and news; most of its articles are written by Penn faculty or students. Harvard Law School's "Forum on Corporate Governance and Financial Regulation" (corpgov.law.harvard.edu) blog and newsletter translate research on corporate governance and financial regulation. Some professional societies have created blogs for their members to translate their research. Examples include the blogs established by the Alliance for Research on Corporate Sustainability (ARCS) ${ }^{17}$ (http://corporate-sustainability.org/blog/) and by the Academy of Management's Organizations and the Natural Environment division (http://one.aom.org/blogs/blog/152).

Some faculty use Twitter to share research insights and comment on news items to their tens of thousands of followers. Leading examples include Austin Goolsbee (University of Chicago economics), Ioannis Ioannou (London Business School strategy), and Justin Wolfers (University of Michigan economics). Some faculty use LinkedIn; Wharton psychology professor Adam Grant's posts, for example, have attracted as many as hundreds of thousands of views.

Faculty from a wide range of disciplines have presented highly engaging TED Talks to convey their research findings to the general public (www.ted.com). For example, MIT's Zeynep 
Ton highlighted her research insights on the relationship between wages and service in a TED Talk that has attracted tens of thousands of views. Our field has much learn from behavioral scientists whose TED Talks have been watched millions of times, such as those by Harvard Business School social psychologist Amy Cuddy, Duke behavioral economist Dan Ariely, and Harvard psychologist Dan Gilbert.

\subsection{Encourage Others to Convey Your Research to Practitioners}

Jane Lubchenco, a professor who has also served as head of a federal agency, observed that academics often "lack the skills to translate complex information into simpler but still accurate information... [and are] uncomfortable with modes of communication that are effective in public communication—storytelling, using analogies and metaphors" (Hoffman et al. 2015: 72). Many are reluctant to invest the time and energy to learn a new writing style. Fortunately, one alternative to your writing an article that conveys your research to practitioners is to encourage someone else who already possesses the requisite skills to do it. This requires identifying suitable blogs — such as those described above — and newspaper or magazine columns that disseminate research findings to practitioners and convincing their authors to cover your research. Doing so enables scholars to leverage someone else's expertise in writing engagingly and his or her established communication channel to practitioners. In some cases, these benefits well exceed the drawback of losing editorial control. Identifying these individuals requires research and networking, and school and university press offices could help develop and disseminate press releases and practitioner articles—-but only if those office's mandate were expanded beyond their typical focus on campus events and administrative news, a step that deans and university presidents should seriously consider. 
Columns. Some faculty write newspaper columns that translate their own and others' research. Examples include a Boston Globe column by Harvard's Edward Glaeser, a Le Monde column by Harvard's Julie Battilana, and the "Economic View" column, by Cornell's Robert Frank, that ran in the New York Times. The New York Times "Upshot" column, written by both professors and professional journalists, compellingly conveys research findings as well.

Trade journals. Trade journals, which contain news and information for specific practitioner groups, can provide a well-targeted channel for OM research insights. Faculty can try to attract coverage by pitching their findings to the editors and writers of journals such as APICS (the journal of the American Production and Inventory Control Society), Hotel Management, Operational Risk \& Regulation, Operations Management, Safety \& Health Practitioner, and Supply Chain Management Review.

\subsection{Communication Style to Reach Practitioners}

Presenting to and writing for practitioners requires a communication style very different from the one in which scholars are immersed. As Hoffman (forthcoming: 13) notes, "Speaking to lay audiences is, in many ways, like speaking another language." For many of us, whatever gifts of engagement and vitality our writing once had has diminished through our doctoral training and the peer-review process. ${ }^{18}$

While it remains important to convey why readers should believe your findings, writing for practitioners requires learning (or rediscovering) how to write journalistically. For example, it often requires engaging the reader right from the start. One way is to set up your research question as an important puzzle that needed solving and then concisely describe your findings. Illustrative anecdotes can be especially helpful. It is rare that a practitioner audience will care to hear about the prior literature, although this is not a universal rule. If, for example, your findings 
contradict prior findings or expand or contract the application of those findings, it certainly makes sense to state what was known before your research. There is little tolerance for academic jargon or esoteric terms such as endogeneity, stochastic, or deterministic. Pages of scholarly description of study details are often consolidated into a single paragraph. Simple graphs often convey the results more clearly to practitioners than statistics and regression coefficients do.

Speculating what our findings might mean beyond our context and sample is often quite difficult for scholars, given our training — and the ever-present reminders by our peer reviewers - to avoid overclaiming. However, practitioner outlets typically want academics to convey the lessons practitioners should take away from our research, which often requires a leap beyond our particular settings. I have found it important to maintain the distinction between what my studies have actually found and what my coauthors and I might reasonably speculate based on our findings.

I often find it helpful to read many articles in the practitioner outlet I am seeking to publish in to absorb its writing style and to learn how other academics have addressed these challenges. Hiring editors have helped me rediscover how to write to nonacademic audiences. University communications departments - and publicists, for schools or professors willing to hire them — can also play an important role by identifying and pitching your research to venues read by your target practitioner audience.

\section{How Academic Institutions Need to Change}

I have focused so far on what scholars can do to increase their own relevance. But academic institutions can also do a lot to foster a research culture that promotes relevance. While others have encouraged business schools to modify their tenure criteria to give more weight to 
relevance when evaluating research (e.g., Walsh 2011), I focus on changes that could be made more immediately by our journals, professional societies, and doctoral programs.

\subsection{Academic Journals}

Journal editors could require (or at least ask) authors to articulate the relevance (or potential relevance) of their research to some set of practitioners. POM recently launched an alternative approach by creating a "POM Practice" area to encourage studies "that highlight problems in a particular industry sector and develop potentially amenable or improved OM solutions," requiring that the problem be "based on a real situation faced by a company (or multiple companies in the same industry)" and that the proposed solution be practical and generalizable. Gallien, Graves, and Scheller-Wolf (forthcoming) suggest that all OM research should be evaluated not only based on its correctness and novelty, but also "how well it applies to the real world." Editors can also accelerate the publication process for the research most relevant to current challenges.

Journals can also create the infrastructure to communicate research insights to practitioners. Some, including Management Science and POM, already provide brief "management insights" for articles, although they are often not readily comprehensible to practitioners and are posted behind a paywall that severely limits practitioners and the press from accessing them. Journals can and should do better ensure the accessibility of such pieces by editing them with an eye toward practitioner readers and making them publicly available. Chris Tang in his role of M\&SOM Editor-in-Chief of recently took such a step when that journal launched "M\&SOM Review" in 2015. This initiative invites authors of recently published M\&SOM articles to write short, publicly-accessible pieces that "distill the[ir] essence" to enable non-OM researchers to "see through the thicket of technical analysis; ... appreciate the relevance 
of various M\&SOM articles; and... apply the research findings" (Tang 2014) and nearly 20 such pieces were posted throughout 2015. More journals should adopt this practice, and go beyond this by providing professional writers to help researchers develop press releases and short pieces that translate their research insights to practitioners and place these in venues that reach practitioners.

Several recent initiatives have begun to address some of these objectives. POM is planning to launch an "online extension" by publishing publicly available short pieces in which scholars convey the managerial insights of their POM articles (Singhal, Sodhi, and Tang 2014). Strategic Management Journal has recently begun encouraging authors of accepted papers to develop short "video abstracts" that highlight research insights, posted publicly at www.youtube.com/user/StrategicMgmtSociety. The new Academy of Management Perspectives initiative to publish research briefs at http://aom.org/amp/researchbriefs is meant to provide "journalistic summaries" of select empirical articles published in other journals that are of interest to scholars and practitioners.

Behavioral Science \& Policy is a new peer-reviewed journal that is attempting to bridge the scholar-practitioner gap in novel ways. It "features short, accessible articles describing actionable policy applications of behavioral scientific research that serves the public interest" and has a "dual-review process. Leading scholars from specific disciplinary areas review articles to assess their scientific rigor; at the same time, experts in relevant policy areas evaluate them for relevance and feasibility of implementation." Moreover, accepted articles "are edited to ensure their accessibility to scientists, policy makers, and lay readers." 


\subsection{Professional Societies}

Professional societies offer a few awards to honor relevant research. For example, the Institute for Operations Research and the Management Sciences (INFORMS) offers a Revenue Management and Pricing Section Practice Award to recognize "outstanding applications of revenue management and pricing techniques" and the Saul Goss Expository Writing Award to researchers whose articles demonstrate a consistently high standard of expository writing. The Academy of Management's Organizations and the Natural Environment (AOM ONE) Division and the Network for Business Sustainability co-sponsor a Research Impact on Practice Award for peer-reviewed research "on any dimension of social or environmental sustainability" that "has important implications for practice." The Strategic Management Society awards its SMS Best Conference Paper Prize for Practice Implications to the best paper with practitioner relevance. Gallien, Graves, and Scheller-Wolf (forthcoming) argue that more prizes and awards for high quality research based on scholar- practitioner collaborations could help increase its prominence and thus encourage more of it.

Professional societies could do a lot more. As Ackoff (1979: 194) suggested nearly 40 years ago, professional societies in the operations field could use their conferences not only to facilitate communication among their academic members, but also to bring in ideas from practitioners "from whom [the academics] can learn something relevant. At least one of the society's meetings each year and one of its publications should be filled with contributions from such outsiders." The POMS annual conferences recently began featuring a POMS Practice Leaders Forum in which practitioners suggest research ideas to academics (Singhal, Sodhi, and Tang 2014). This is a promising idea that can massively scale the engagement that occurs at the specialized crossover conferences described earlier. 
Ackoff (1979: 195) also recommended that professional societies establish "at least one journal addressed to their actual and potential consumers...that might be called For Managers Only... [to] contain relevant articles addressed to managers. Each member of the Society would designate a manager to whom a copy would be sent at no cost." While professional societies have launched crossover journals like Academy of Management Perspectives and INFORM's Interfaces, their attempt to reach two disparate audiences — academics and practitioners - may be limiting their success in reaching practitioners. Ackoff's suggestion to narrow the target audience of certain journals to managers could address this.

Professional societies could also take the lead in better equipping faculty to successfully engage with practitioners by including sessions on managing media inquiries, writing op-eds and for the trade press, disseminating research insights through social media, and learning how to identify the key publications and reporters with whom to develop relationships. Stanford University's Leopold Leadership Program, for example, trains midcareer academic scientists from across North America to learn how to "engage effectively with leaders in the public and private sectors who face complex decisions about sustainability and the environment." ${ }^{\prime 19}$ The non-profit COMPASS was created to help ocean scientists better convey insights of marine research to the general public, policymakers, and managers (Smith et al. 2013). Professional societies or universities could develop similar initiatives for OM scholars (and researchers from many other business school domains) to learn how to more effectively communicate research insights to practitioners.

\subsection{Doctoral Programs}

We also need to encourage and train our doctoral students to nurture the desire to conduct relevant research and to acquire the knowledge to do, including by encouraging them to engage 
with practitioners. Vermeulen (2005: 980-981) observed by reading doctoral program applications "that very few people aspire to become business academics with the intention to publish journal articles that will only be read by other academics (at best); rather, these applicants are much more inspired by the thought of gaining and developing truly relevant knowledge that might change the world of organizations." Hoffman (forthcoming: 6) similarly notes that "[m]any graduate students report that they have chosen a research career precisely because they want to contribute to the real world; to offer their knowledge and expertise in order to make a difference.” Therefore, we may not need to convince them to pursue relevant research but rather to show them how to avoid the insular scholarly view and style that will frustrate their original ambition to serve a real-world audience. We can begin right away by having our students participate in the site visits and interviews described earlier. We can also shift our program requirements to ensure that all doctoral students engage with practitioners. At Harvard Business School, we have begun institutionalizing this idea with a requirement that doctoral students spend a week or two in the field, typically in their second or third year. We hope that this will not only force them to learn about practitioners' experiences and challenges, but will also engender a habit of engagement to ensure that their research remains relevant throughout their careers. ${ }^{20}$

\section{Final Thoughts}

One concern I often hear about conducting more relevant research is that it will take more time. Many of the approaches described here do require time, although most do not take much: perhaps a few additional days per research project to conduct some due diligence and to obtain feedback. Given the time we already invest in any research project, a few days of due diligence does not seem too high a price to pay, even in one's pre-tenure years when the opportunity cost 
of time seems especially high. And against the initial investment one must balance the potential for a positive feedback loop. Engaging with practitioners to develop relevant research not only helps improve the research, but also increases the likelihood that practitioners will subsequently read and appreciate a translation of that work. This can yield practitioner inquiries that can, in turn, provide access to new field sites and new datasets, including proprietary data that has never been shared with scholars before and can lead to novel lines of inquiry.

In the end, how can we know if our field has succeeded in making our research relevant? As Hayes noted more than a decade ago, we'll know when OM faculty "become the people to whom high-level, practicing operations managers and consultants turn for information and insight about the most important problems confronting them" (Hayes 2000: 110). But I suspect that day when practitioners will regularly seek to learn from us will occur only after enough of us scholars regularly seek to learn from them.

\section{References}

Ackoff, R. L. 1979. Resurrecting the future of operational research. Journal of the Operational Research Society 30(3): 189-199.

Beyer, J. M. 1982. Introduction to the special issue on the utilization of organizational research. Administrative Science Quarterly 27(4): 588-590.

Blanding, M. 2015. Business research that makes for smarter public policy. HBS Working Knowledge, October 19, http://hbswk.hbs.edu/item/business-research-that-makes-forsmarter-public-policy.

Brooks, D. 2014. Professors, we need you! New York Times (February 16): SR11.

Buchbinder, R., C. Maher, I. A. Harris. 2015. Setting the research agenda for improving health care in musculoskeletal disorders. Nature Reviews Rheumatology 11(10): 597-605.

Cachon, G. P. 2012. What is interesting in operations management? Manufacturing \& Service Operations Management 14(2): 166-169.

Camm, J. D. 2015. In memoriam—Robert E. D. (Gene) Woolsey. Interfaces 45(4): 369.

Cohen, D. J. 2007. The very separate worlds of academic and practitioner publications in human resource management: Reasons for the divide and concrete solutions for bridging the gap. Academy of Management Journal 50(5): 1013-1019. 
Corbett, C. J., L. N. Van Wassenhove. 1993. The natural drift: What happened to operations research? Operations Research 41(4): 625-640.

Daft, R. L., A. Y. Lewin. 1990. Can organizational studies begin to break out of the normal science straitjacket? An editorial essay. Organization Science 1(1): 1-9.

Denisi, A. S. 2010. Challenges and opportunities for the academy in the next decade. Academy of Management Review 35(2): 190-201.

Emerald Group. 2014. How to... write for a practitioner audience. Emerald Group Publishing Limited. http://www.emeraldgrouppublishing.com/authors/guides/write/practitioner.htm.

Fisher, M. L. 2007a. Bob Hayes: Forty years of leading operations management into uncharted waters. Production and Operations Management 16(2): 159-168.

Fisher, M. L. 2007b. Strengthening the empirical base of operations management. Manufacturing \& Service Operations Management 9(4): 368-382.

Gallien, J. 2013. Motivating research through industry interaction. Proceedings of the Utah Winter Operations Conference. February 9. http://org.business.utah.edu/opsconf/?q=node/43.

Gallien, J., S. C. Graves, A. Scheller-Wolf. Forthcoming. Practice-based research in operations management: What it is, why do it, related challenges, and how to overcome them.

Manufacturing \& Service Operations Management. http://dx.doi.org/10.1287/msom.2015.0566

Gallien, J., A. Scheller-Wolf. 2013. Call for papers-Proposal for an M\&SOM special issue on practice-focused research. Manufacturing \& Service Operations Management 15(2): 1-2.

Graves, S. C. 2009. A letter from the editor. Manufacturing \& Service Operations Management 11(1): 1-3.

Gulati, R. 2007. Tent poles, tribalism, and boundary spanning: The rigor-relevance debate in management. Academy of Management Journal 50(4): 775-782.

Hall, J. R., S. W. Hess. 1978. OR/MS: Dead or dying? RX for survival. Interfaces 8(3): 42-44.

Hambrick, D. C. 1994. 1993 presidential address: What if the academy actually mattered? Academy of Management Review 19(1): 11-16.

Hayes, R. H. 1998. Developing POM faculty for the 21st century. Production and Operations Management 7(2): 94-98.

Hayes, R. H. 2000. Towards a "new architecture" for POM. Production and Operations Management 9(2): 105-110.

Hoffman, A. J. 2015. Isolated scholars: Making bricks, not shaping policy. Chronicle of Higher Education, Feb. 9.

Hoffman, A. J. Forthcoming. Reflections: Academia's emerging crisis of relevance and the consequent role of the engaged scholar. Journal of Change Management. http://dx.doi.org/10.1080/14697017.2015.1128168

Hoffman, A.J., K. Ashworth, C. Dwelle, P. Goldberg, A. Henderson, L. Merlin, Y. Muzyrya, N.J. Simon, V. Taylor, C. Weisheit, S. Wilson. 2015. Academic Engagement in Public and 
Political Discourse: Proceedings of the Michigan Meeting, May 2015. Ann Arbor, MI: Michigan Publishing. http://quod.lib.umich.edu/m/mm/

Mowday, R. T. 1997. Reaffirming our scholarly values. Academy of Management Review 22(2): 335-345.

Nicolai, A., D. Seidl. 2010. That's relevant! Different forms of practical relevance in management science. Organization Studies 31(09-10): 1257-1285.

Norden, P. V. 1970. A message from the president. Interfaces 1(1): 1.

O'Hara, C. 2014. How to improve your business writing. Harvard Business Review digital article, November 20, https://hbr.org/2014/11/how-to-improve-your-business-writing.

Panda, A., R. K. Gupta. 2014. Making academic research more relevant: A few suggestions. IIMB Management Review 26(3): 156-169.

Singhal, K., M. S. Sodhi, C. S. Tang. 2014. POMS initiatives for promoting practice-driven research and research-influenced practice. Production and Operations Management 23(5): $725-727$.

Smith B., N. Baron, C. English, H. Galindo, E. Goldman, K. McLeod, M. Miner, E. Neeley. 2013. COMPASS: Navigating the rules of scientific engagement. PLoS Biology 11(4): e1001552.

Tang, C. 2014. "Welcome to MSOM Review," December 2. https://www.informs.org/Blogs/MSOM-Blogs/M-SOM-Review/Welcome-to-MSOM-Review.

Thomas, K. W., W. G. Tymon, Jr. 1982. Necessary properties of relevant research: Lessons from recent criticisms of the organizational sciences. Academy of Management Review 7(3): 345352.

Tushman, M. L., C. A. I. O'Reilly. 2007. Research and relevance: Implications of Pasteur's quadrant for doctoral programs and faculty development. Academy of Management Journal 50(4): 769-774.

Van Mieghem, J. A. 2013. Three Rs of operations management: Research, relevance, and rewards. Manufacturing \& Service Operations Management 15(1): 2-5.

Vermeulen, F. 2005. On rigor and relevance: Fostering dialectic progress in management research. Academy of Management Journal 48(6): 978-982.

Vizecky, K., O. El-Gayar. 2011. Increasing research relevance in DSS: Looking forward by reflecting on 40 years of progress. Proceedings of the 44th Hawaii International Conference on System Sciences (January 4-7): 1-9. doi: 10.1109/HICSS.2011.239.

Walsh, J. P. 2011. 2010. Embracing the sacred in our secular scholarly world. Academy of Management Review 36(2): 215-234.

Wein, L. M. 2009. Homeland security: From mathematical models to policy implementation: The 2008 Philip McCord Morse Lecture. Operations Research 57(4): 801-811.

Woolsey, R. E. D. 2003 Real World Operations Research: The Woolsey Papers. Marietta, Georgia: Lionheart Publishing. 


\section{Endnotes}

${ }^{1}$ Similar concerns have been voiced recently about an unfortunate lack of engagement by scholars in public and political discourse, based in part on scholars choosing to work on problems disconnected from society's pressing problems (e.g., Hoffman et al. 2015, Hoffman forthcoming).

${ }^{2}$ For an interesting set of Woolsey's writings about the need for more practice-focused research and teaching, see Woolsey (2003).

${ }^{3}$ For a taxonomy of various forms of relevance, see Nicolai and Seidl (2010).

${ }^{4}$ The need for more relevant research is a concern in many other academic disciplines and departments beyond business schools. Decision sciences and medical research, for example, face similar issues (e.g., Vizecky and ElGayar 2011; Buchbinder, Maher, and Harris 2015).

${ }^{5}$ Wein (2009: 808) describes a similar heuristic to decide which research projects are likely to have a big impact on public policy: "My rule of thumb for working on a problem was whether the answers to the following four questions were yes, no, no, and yes: Is the problem very important (i.e., could it directly or indirectly lead to catastrophic consequences)? Has the problem been sufficiently addressed in the academic literature? Has the problem been satisfactorily addressed by policy makers? Would the problem be fun (i.e., sufficiently challenging) to work on?" A useful alternative set of assessment criteria is provided in the Call for Papers for the Special Issue on PracticeFocused Research in Manufacturing \& Service Operations Management: "How important and challenging is the OM problem considered? How applicable and relevant are the research results presented for practitioners - are the results having a significant effect on practice now and/or are they likely to have a significant effect in the near future? How novel is the problem considered, the methodological contribution, and/or the insights generated? How large and convincing is the impact reported (if applicable)?" (Gallien and Scheller-Wolf 2013:2).

${ }^{6}$ For example, managerial conferences relevant to my sustainable operations research include the Ceres annual conference (a "network of investors, companies and public interest groups to accelerate and expand the adoption of sustainable business practices and solutions to build a healthy global economy"), the National Association for Environmental Management (NAEM) annual conference (which purports to be "the largest annual gathering for environment, health and safety (EHS) and sustainability decision-makers"), and GRI Global Conferences (the "world's largest gathering of leaders, thinkers and doers in the field of sustainability reporting"). I've also met managers engaged in global supply chain auditing by attending and presenting at the Ethical Sourcing Forum, an annual practitioner conference.

${ }^{7}$ Regulatory workshops at which I've presented include the U.S. Environmental Protection Agency's "National Training Conference on the Toxics Release Inventory" and "Next Generation Environmental Compliance Workshop," and the U.S. Department of Labor's "Use of Workers' Compensation Data for Occupational Safety and Health" workshop.

${ }^{8}$ The Consortium for Operational Excellence in Retailing conference is rooted in a research project Ananth Raman and Marshall Fischer started in 1997 that sought to address the question, "How will advances in information technology change the way retailers forecast demand and plan supply?" With assistance from Harvard's Walt Salmon, they recruited 32 retailers to participate, conducted multi-day site visits to most of them to understand their operations, and conducted research projects with some of them to improve their operations. The initial conferences, held in 1998 at Harvard and in 1999 at Wharton, reported progress of these projects to the 32 participating retailers. Conferences have been held nearly annually since then with an increasing group of participants. For more information, see Consortium for Operational Excellence in Retailing (COER), The Fishman-Davidson Center for Service and Operations Management at The Wharton School, http://opim.wharton.upenn.edu/fd/partnerships.php\#coer, accessed August 2015. For information on the 2015 COER conference, see http://www.hbs.edu/faculty/conferences/2015-coer/Pages/default.aspx, accessed July 2015.

${ }^{9}$ Wharton Service Supply Chain Thought Leaders Forum, http://opim.wharton.upenn.edu/fd/forum, accessed July 2015. 
10 "Collaborative Academic/Practitioner Workshop on Operational Innovation," organized by Jérémie Gallien, Karan Girotra, Marcelo Olivares, Kamalini Ramdas, and Jeff Skinner, held at London Business School on July 2526, 2013.

${ }^{11}$ For details on the Transparency and Accountability: The Role of Information Disclosure workshop, see http://www.hbs.edu/faculty/conferences/2008-transparency-and-accountability/Pages/agenda.aspx.

${ }^{12}$ The Research on Effective Government: Inspection and Compliance workshop was described in Blanding (2015). For more information, see the conference websites at http://mcep.umd.edu/event/research-effective-governmentinspection-and-compliance-workshop/ and http://www.hbs.edu/faculty/conferences/2015-research-on-effectivegovernment/Pages/default.aspx, accessed January 2016.

${ }^{13}$ For additional benefits of and approaches to observing and learning from practitioners in action, see Hayes (2000).

${ }^{14}$ Academy of Management, “Academy of Management Perspectives,” http://aom.org/amp/, accessed January 2016.

${ }^{15}$ Disclosure: Ed Kaplan was my MBA professor at Yale School of Management in the mid-1990s.

${ }^{16}$ Many more blogs on OM topics are listed at http://www.supplychainopz.com/p/blogroll_6.html and http://www.supplychainopz.com/2014/03/scm.html.

${ }^{17}$ Disclosure: I am a board member of the Alliance for Research on Corporate Sustainability.

${ }^{18}$ A full treatment of this topic is beyond the scope of this article and there are plenty of resources offering concise advice, such as Emerald Group (2014) and O'Hara (2014).

${ }^{19}$ Leopold Leadership Program, "Fellowship Overview,". http://leopoldleadership.stanford.edu/fellowshipinformation, accessed January 2016.

${ }^{20}$ For other ways doctoral programs should change to better foster research that is both relevant and rigorous, see Tushman and O'Reilly (2007). 